\title{
Physical and optical properties of atmospheric aerosols by in-situ and radiometric measurements
}

\author{
M. Calvello ${ }^{1}$, F. Esposito ${ }^{1,2}$, G. Pavese ${ }^{1}$, and C. Serio ${ }^{2}$ \\ ${ }^{1}$ Consiglio Nazionale delle Ricerche-Istituto di Metodologie per l'Analisi Ambientale (CNR-IMAA), C. da S. Loja, 85050 \\ Tito Scalo, Potenza, Italy \\ ${ }^{2}$ Dipartimento di Ingegneria e Fisica dell'Ambiente, Università della Basilicata, Viale dell'Ateneo Lucano n. 10, 85100 \\ Potenza, Italy
}

Received: 13 October 2009 - Published in Atmos. Chem. Phys. Discuss.: 27 November 2009

Revised: 10 February 2010 - Accepted: 19 February 2010 - Published: 2 March 2010

\begin{abstract}
Physical and optical properties of atmospheric aerosols collected by using a high resolution $(1.5 \mathrm{~nm})$ spectroradiometer (spectral range $400-800 \mathrm{~nm}$ ), a 13-stage Dekati Low Pressure Impactor (size range $30 \mathrm{~nm}-10 \mu \mathrm{m}$ ), and an AE31 Aethalometer (7 wavelenghts from $370 \mathrm{~nm}$ to $950 \mathrm{~nm}$ ), have been examined in a semi-rural site in Southwest Italy (Tito Scalo, $40^{\circ} 35^{\prime} \mathrm{N}, 15^{\circ} 41^{\prime} \mathrm{E}, 750 \mathrm{~m}$ a.s.l.). In particular, daily averaged values of AOD and Ångström turbidity parameters from radiometric data together with masssize distributions from impactor data and Black Carbon (BC) concentrations have been analyzed from May to October 2008. Furthermore, by inverting direct solar radiances, aerosol columnar number and volume size distributions have been obtained for the same period. The comparison of different observation methods, allowed to verify if, and in what conditions, changes in aerosol properties measured at ground are representative of columnar properties variations. Agreement between columnar and in-situ measurements has been obtained in case of anthropogenic aerosol loading, while in case of Saharan dust intrusions some discrepancies have been found when dust particles were located at high layers in the atmosphere $(4-8 \mathrm{~km})$ thus affecting columnar properties more than surface ones. For anthropogenic aerosols, a good correlation has been confirmed through the comparison of fine aerosol fraction contribution as measured by radiometer, impactor and aethalometer, suggesting that, in this case, the particles are more homogeneously distributed over the lower layers of atmosphere and columnar aerosol optical properties are dominated by surface measured component.
\end{abstract}

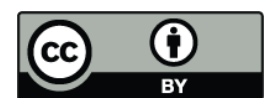

Correspondence to: M. Calvello (calvello@imaa.cnr.it)

\section{Introduction}

At present time aerosols are recognized to be responsible for a significant impact on climate change affecting our environment. IPCC 2007 refers to aerosol radiative forcing, through direct, indirect and semi-direct effects, as a problem with a medium-low level of scientific understanding due to the strong unhomogeneity of aerosol sources and the high spatial and temporal variability of aerosol properties in the atmosphere. Uncertainty in aerosol property retrieval requires the merging of well integrated instrumentation since no single type of observation is sufficient to predict aerosol properties in an adequate way. Thus, according to IPCC 2007, improved and intensified in situ observations together with remote sensing of aerosols could better constrain the range of aerosol radiative forcing.

Radiometric remote sensing techniques are a very powerful tool to investigate aerosol optical properties on the vertical column. AOD values can be measured to estimate aerosol loading in the atmosphere. Moreover the analysis of AOD spectral dependence expressed by the Ångström exponent $\alpha$ and the study of a relationship between AOD and $\alpha$ can be useful to distinguish different aerosol types. On this subject Masmoudi et al., 2003 identified aerosol source region in different sites of the Mediterranean basin analysing Ångström exponent $\alpha$ variation as a function of the aerosol optical thickness at $870 \mathrm{~nm}$. The same kind of analysis is carried out by Mukai et al., 2006, and Pace et al., 2006 over an urban area in Japan and the Mediterranean Sea respectively. As a further support to aerosol characterization, inversions can be performed from radiometric measurements to obtain both columnar volume and number size distributions (Cachorro et al., 2008; Lyamani et al., 2005; Pavese et al., 2009; Perrone

Published by Copernicus Publications on behalf of the European Geosciences Union. 


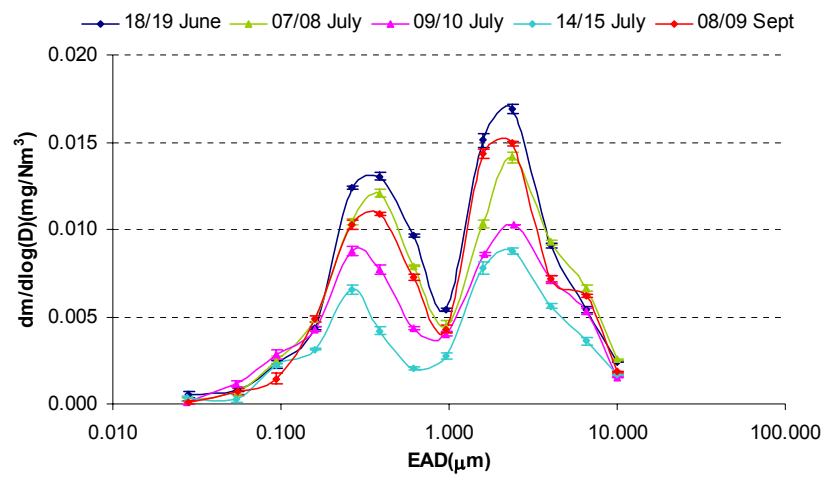

Fig. 1. Mass size distributions at ground level from DLPI data for 18/19 June, 7/8, 9/10 July, and 14/15 July and 8/9 September. Coarse mode at $2.4 \mu \mathrm{m}$ prevails on accumulation mode at about $0.3 \mu \mathrm{m}$.

et al., 2005). Observations of aerosol properties from radiometric measurements are widely available so far, consider for example AERONET and SKYNET networks. However, for a better understanding of the aerosol role in atmospheric processes especially near the ground, where most anthropogenic aerosol are concentrated, measurements in the nearground layer of the atmosphere are desirable. Furthermore, in cases when different layers of aerosol at different heights are present, the uncertainties in column-integrated aerosol optical and physical parameters retrievals, could be assessed thanks to in situ observations. In situ instruments allow further to obtain very precise information about local trends that are unobtainable through other means. Existing radiometric and in situ integrated measurements have led to important results, showing in most cases a good correlation between surface and columnar aerosol properties (Chaudhry et al., 2007; Cheng et al., 2008; Choi et al., 2008; Gerasoupoulos et al., 2007; Mukai et al., 2006, Shafër et al., 2008; Schaap et al., 2009). This has led to an increasing interest in expanding coverage for integrated measurements into key areas representative of the different aerosol types.

The main goal of this work is to study optical and physical properties of aerosols by the use of different observation techniques such as ground-based radiometric, in-situ gravimetric and filter-absorbing techniques. For an in-depth analysis, ground-level and columnar size distributions have been compared directly for days of contemporary measurements. Attention has been focused on particulate fine fraction component through Black Carbon (BC) concentration measurements due to its important role in climate forcing as the major solar radiation absorbing component of atmospheric aerosols. The aethalometer is one of the most common instrument for measuring real-time $\mathrm{BC}$ concentrations with more than one thousand instruments used all around the world (Snyder et al., 2007). It is simple to use, quite inexpensive, allowing samplings to be subjected to further analy- sis. In this work, aethalometer measurements of $\mathrm{BC}$ concentrations combined with impactor and radiometric estimates of aerosol physical properties contributed to a better understanding of $\mathrm{BC}$ contribution to the fine fraction of aerosol.

All measurements have been performed in a semi-rural site belonging to the Mediterranean area that is a proper site for monitoring variability of aerosol properties in a complete way due to the influence of different air masses, as confirmed also by systematic LIDAR measurements for vertical optical and physical aerosols properties study (Barnaba et al., 2007; Papayannis et al., 2005). In particular seaborne particles both from the Mediterranean itself and transported from the Atlantic Ocean are present, together with dust from Sahara desert and polluted and smoke aerosols mainly from Central and Eastern Europe. This mix of aerosols originating from different sources, typical of almost all the Mediterranean environment, causes the site to be very complex to investigate. Combining radiometric, impactor and aethalometer measurements, at least on a campaign basis so far, could provide a closure between optical and physical properties of all these different aerosol types.

\section{Field campaign}

\subsection{Sampling site}

The measurement site, located in South-Italy (Tito Scalo, $40^{\circ} 60^{\prime} \mathrm{N}, 15^{\circ} 72^{\prime} \mathrm{E}, 750 \mathrm{~m}$ a.s.l.), is a very small industrial zone placed in a large rural area with some anthropogenic aerosol local source impacting the sampling location ( some little plants and a main road passing at a distance of about $1 \mathrm{~km}$ ). During the sampling period, mainly summer, frequent local smoke events from neighbouring woods have been registered. Moreover the site is exposed to receive aerosol loading from air mass transport both anthropogenic from NorthEastern Europe and dust intrusion from Sahara desert together with marine particles which are an almost constant component at the site due to the closeness of Tyrrhenian, Adriatic and Ionian seas (respectively $70 \mathrm{~km}, 90 \mathrm{~km}$, and $95 \mathrm{~km})$.

\subsection{Measurements and methods}

A Dekati Low Pressure Impactor (DLPI hereafter) has been used to obtain the aerosol mass size distributions at ground level with the instrument inlet placed at about $2 \mathrm{~m}$ above ground. The DLPI has a size range from 0.03 to $10.0 \mu \mathrm{m}$ and a flow rate of $30 \mathrm{l} / \mathrm{min}$ with $50 \%$ stage cut off Equivalent Aerodynamic Diameters (EAD) at 0.029, 0.056, 0.095, $0.158,0.264,0.383,0.610,0.939,1.577,2.354,3.928,6.471$, $9.769 \mu \mathrm{m}$. Aerosols have been collected on $25 \mathrm{~mm}$ diameter Nucleopore polycarbonate filters for gravimetric analysis with a sampling time of $24 \mathrm{~h}$. Mean daily values of air temperature, pressure and relative humidity measured at the impactor inlet were used to obtain the normalised sampled 
Table 1. Modal EAD values for mass size distributions derived from impactor sampling. Dates in the table are reported considering first and second day of each $24 \mathrm{~h}$ sampling.

\begin{tabular}{lllll}
\hline Date & EAD $(\mu \mathrm{m})$ Mode 0 & $\operatorname{EAD}(\mu \mathrm{m})$ Mode 1 & $\operatorname{EAD}(\mu \mathrm{m})$ Mode 2 & $\operatorname{EAD}(\mu \mathrm{m})$ Mode 3 \\
\hline 18/19 June & 0.093 & 0.387 & 2.393 & \\
23/24 June & & 0.327 & 2.401 & 6.615 \\
24/25 June & 0.093 & 0.388 & 2.404 & \\
7/8 July & & 0.387 & 2.398 & 6.539 \\
9/10 July & & 0.266 & 2.404 & 6.615 \\
14/15 July & 0.093 & 0.266 & 2.401 & 6.615 \\
16/17 July & 0.055 & 0.266 & 2.401 & 6.606 \\
28/29 July & 0.093 & 0.388 & 1.606 & 6.606 \\
30/31 July & & 0.388 & 2.401 & \\
4/5 August & & 0.327 & 2.401 & 6.587 \\
8/9 September & 0.055 & 0.387 & 2.395 & 6.539 \\
17/18 September & 0.055 & 0.265 & 2.372 & \\
7/8 October & & 0.265 & 2.378 & \\
\hline
\end{tabular}

Table 2. Mean daily values of AOD (@500 and $780 \mathrm{~nm}$ ), of $\alpha$ and $\beta$ parameters. Values of standard deviation $\sigma$ are reported.

\begin{tabular}{lllll}
\hline Date & $<\mathrm{AOD}> \pm \sigma(500 \mathrm{~nm})$ & $<\mathrm{AOD}> \pm \sigma(780 \mathrm{~nm})$ & $<\alpha> \pm \sigma$ & $<\beta> \pm \sigma$ \\
\hline 27 May & $0.20 \pm 0.01$ & $0.18 \pm 0.02$ & $0.34 \pm 0.02$ & $0.16 \pm 0.02$ \\
28 May & $0.51 \pm 0.01$ & $0.42 \pm 0.05$ & $0.39 \pm 0.01$ & $0.39 \pm 0.02$ \\
24 June & $0.20 \pm 0.01$ & $0.08 \pm 0.03$ & $1.90 \pm 0.03$ & $0.06 \pm 0.01$ \\
25 June & $0.31 \pm 0.01$ & $0.17 \pm 0.03$ & $1.38 \pm 0.02$ & $0.12 \pm 0.02$ \\
8 July & $0.37 \pm 0.01$ & $0.34 \pm 0.04$ & $0.33 \pm 0.01$ & $0.30 \pm 0.01$ \\
9 July & $0.13 \pm 0.01$ & $0.09 \pm 0.03$ & $0.82 \pm 0.02$ & $0.07 \pm 0.02$ \\
10 July & $0.26 \pm 0.01$ & $0.16 \pm 0.04$ & $1.11 \pm 0.02$ & $0.12 \pm 0.01$ \\
16 July & $0.11 \pm 0.01$ & $0.06 \pm 0.03$ & $1.33 \pm 0.04$ & $0.05 \pm 0.02$ \\
17 July & $0.38 \pm 0.01$ & $0.35 \pm 0.11$ & $0.19 \pm 0.02$ & $0.34 \pm 0.01$ \\
29 July & $0.24 \pm 0.01$ & $0.10 \pm 0.04$ & $1.70 \pm 0.03$ & $0.07 \pm 0.01$ \\
30 July & $0.26 \pm 0.01$ & $0.11 \pm 0.03$ & $1.91 \pm 0.02$ & $0.08 \pm 0.02$ \\
31 July & $0.21 \pm 0.01$ & $0.09 \pm 0.03$ & $1.89 \pm 0.03$ & $0.06 \pm 0.02$ \\
5 August & $0.22 \pm 0.01$ & $0.11 \pm 0.03$ & $1.56 \pm 0.02$ & $0.08 \pm 0.01$ \\
6 August & $0.44 \pm 0.02$ & $0.36 \pm 0.06$ & $0.34 \pm 0.01$ & $0.34 \pm 0.02$ \\
9 September & $0.13 \pm 0.01$ & $0.09 \pm 0.04$ & $1.23 \pm 0.03$ & $0.06 \pm 0.01$ \\
\hline
\end{tabular}

volume. Filters were stored into a conditioned room for 24 $\mathrm{h}$ before and after exposure at $50 \pm 5 \mathrm{RH} \%$ and $20 \pm 5^{\circ} \mathrm{C}$. After the equilibration, before and after exposure, filters were weighted on a microbalance (Mettler Toledo MX5 Type - weighing accuracy of $\pm 1 \mu \mathrm{g}$ ) for gravimetric analysis. Weighing was performed in the same conditioned room. Repeated weighing was performed for each filter with a third weighing when the first two were not within $5 \mu \mathrm{g}$. The mean of the two closest weighing was used for the analysis. Field blanks were used to calculate the limit of detection (LOD) for the whole procedure. A number of 13 samplings were carried out with one or at most two samplings per week for the period June-October 2008. From direct mass measurements on sampled filters, the mass size distributions are simply derived from:

$$
\frac{d m}{d \log (D)}=\frac{d M_{i}}{V_{N} \cdot \log \left(D_{50, i+1} / D_{50, i}\right)}
$$

where $d M_{i}$ is the mass collected on the $i$-th stage $(i=1-$ 13), $V_{N}$ is the normalised sampled volume, and $D_{50, i}$ and $D_{50, i+1}$ are the cut-off equivalent aerodynamic diameters for the $i$-th stage and the $i+1$-th stage respectively (Baron and Willeke, 2001).

Direct solar irradiance spectra have been measured by the high resolution Ocean Optics S2000 spectroradiometer covering the spectral range $400-800 \mathrm{~nm}$. The solar diffuse light component has been excluded from the incoming beam by the optic field of view of about $1^{\circ}$. Measurements were carried out in cloudless conditions, all along the day, recording spectra every $15 \mathrm{~min}$. More than $500 \mathrm{spec}-$ tra have been collected during the period May-September 
Table 3. Aerosol classification based on different AOD (@500 and $780 \mathrm{~nm})$ and $\alpha$ and $\beta$ range of variations.

\begin{tabular}{llll}
\hline Parameters & Saharan dust & Anthropogenic & Back-ground/marine \\
\hline AOD $(500 \mathrm{~nm})$ & $0.37-0.51$ & $0.2-0.31$ & $<0.2$ \\
AOD $(780 \mathrm{~nm})$ & $0.34-0.42$ & $0.08-0.17$ & $0.06-0.09$ \\
$\alpha$ & $0.19-0.39$ & $1.11-2.09$ & $0.7-1.3$ \\
$\beta$ & $0.30-0.39$ & $0.06-0.12$ & $<0.1$ \\
\hline
\end{tabular}

2008 on 14 measurements days. Aerosol Optical Depth has been estimated by the Langley calibration procedure out of the strong gaseous absorption bands (Esposito et al., 2004). A correction has been made for the ozone Chappuis band $(0.45-0.70 \mu \mathrm{m})$ using ozone content daily data available on the TOMS (Total Ozone Map Spectrometer) web site (toms.gsfc.nasa.gov/eptoms/ep.html).

The estimation of the Ångström parameters $\alpha$ and $\beta$ has been obtained by a fitting procedure applied to the wellknown Ångström turbidity formula relating AOD to the wavelength.

Finally, aerosol number and volume size distributions have been derived from AOD through a modified non-parametric inversion technique described in detail in Esposito et al., 2004.

For the entire measurement period about $70 \%$ of contemporary radiometric and gravimetric measurements have been obtained, with radiometric measurements achievable only during the day and with clear sky conditions, whereas impactor measurements are only subject to the no-rain condition.

Black Carbon measurements were carried out from May 2008 to October 2008 with a seven wavelength Aethalometer (Magee Scientific, model AE31, $\lambda$ 370, 470, $520,590,660,880,950 \mathrm{~nm}$ ). The size selective inlet (aerodynamic particle diameter $<2.5 \mu \mathrm{m}$ ) was placed at about $2 \mathrm{~m}$ above ground. Aerosols were collected on a quartz fiber tape with a time resolution of $5 \mathrm{~min}$ at a flow rate of $3.9 \mathrm{lpm}$. Optical attenuation measurements through the filter allowed to estimate the $\mathrm{BC}$ mass concentration using the constant mass absorption cross section value of $16.6 \mathrm{~m}^{2} \mathrm{~g}^{-1}$ at $880 \mathrm{~nm}$ recommended by the manufacturer. In this phase, no correction has been performed either for the shadowing effect and for the scattering offset (Collaud Coen et al., 2009), considering first results obtained here useful for a first qualitative $\mathrm{BC}$ data analysis. In a further step, a correction procedure is expected to be carried out for a more quantitative analysis.

To better interpret surface and columnar data comparison, back trajectory analysis has been performed using the HYbrid Single-Particle Lagrangian Integrated Trajectory (HYPLIT4) model (Draxler and Rolph, 2003). In particular, 5day backward trajectories have been calculated at 12 different endpoints from 500 to $6000 \mathrm{~m}$ a.g.l. ARL/GDAS meteorological database (spatial resolution $1^{\circ}$, temporal reso- lution $3 \mathrm{~h}$ ) from NOAA Air Resources Laboratory's web server (http://www.arl.noaa.gov/READYamet.php) has been employed as input for the HYSPLIT4 model.

Possible Saharan dust intrusions have been verified even through the DREAM (Dust REgional Atmospheric Model) model and the Navy Aerosol Analysis and Prediction System (NAAPS) aerosol maps, provided from the Barcelona Supercomputing Center (http://www.bsc.es/projects/earthscience/ DREAM/) and the Naval Research Laboratory (http://www. nrlmry.navy.mil/aerosol/), respectively. NAAPS aerosol maps were used also to obtain sulphate and smoke concentrations distribution. For investigation of fire areas, daily active fire hot spot detections (FIRMS maps) were used from Web Fire Mapper (http://maps.geog.umd.edu).

\section{Results and discussion}

\subsection{Aerosol properties from ground-level DLPI measurements}

Typical mass size distributions obtained from DLPI data for the analyzed measurement period show a prevailing bimodal pattern with the accumulation mode oscillating in the range $0.27 \mu \mathrm{m}-0.39 \mu \mathrm{m}$ and a coarse mode centred at $2.4 \mu \mathrm{m}$. Some distributions show a multimodal pattern with alternatively three more modes: two ultra-fine at $0.055 \mu \mathrm{m}$ and $0.093 \mu \mathrm{m}$ and a coarse at $6.6 \mu \mathrm{m}$. The accumulation mode is always present and can be attributed to the local traffic emissions in accordance with what found in Chuaybamroong et al. (2006) for traffic associated mass size distributions. In that work, aerosol mass size distributions have been obtained with a MOUDI, sampling different aerosol types near their corresponding point sources: a cement plant stack for anthropogenic secondary aerosols, an agricultural farm for soil dust aerosols, the Atlantic Ocean for seaborne particles. In the case of traffic aerosol, measured near the footpath of a very busy street without other major aerosol sources, mass size distributions showed a peak in the dimensional range $0.32-0.56 \mu \mathrm{m}$. As it will be seen later, for our measurements this mode becomes more intense when air masses from North-Eastern Europe are transported to the sampling site or when local smoke events take place. Modal diameter centred at about $2.4 \mu \mathrm{m}$ is also always present being attributable to the local sources of dust like soil (Chuaybamroong et al., 2006; Salma et al., 2002) or to the marine aerosol that are, as verified from back-trajectories analysis, a constant component of air mass transport and loading on the sampling site. As for the accumulation mode, also this second mode increases for long-range transport events in this case from Saharan desert. This is in accordance with what is commonly found in literature where dust mass size distributions are characterized by a dominant coarse mode with modal diameter $>2 \mu \mathrm{m}$ (Clarke et al., 2004; Park and Kim, 2006; Tegen et al., 2006). As regards marine aerosol, in literature 


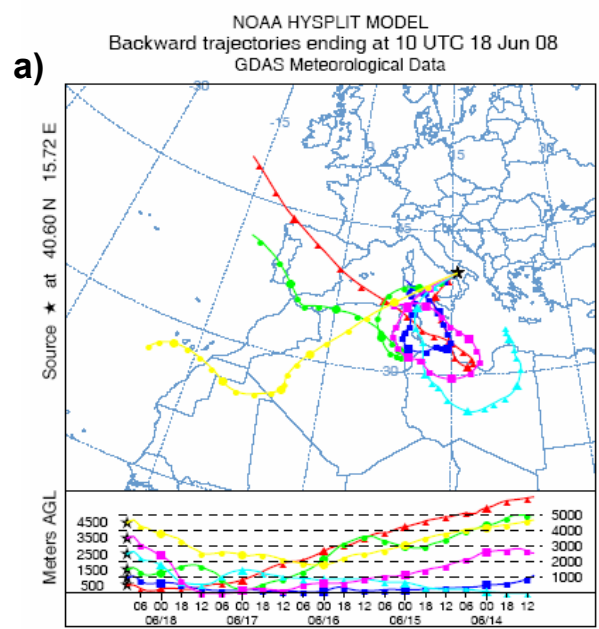

NOAA HYSPLIT MODEL

Backward trajectories ending at 20 UTC 18 Jun 08

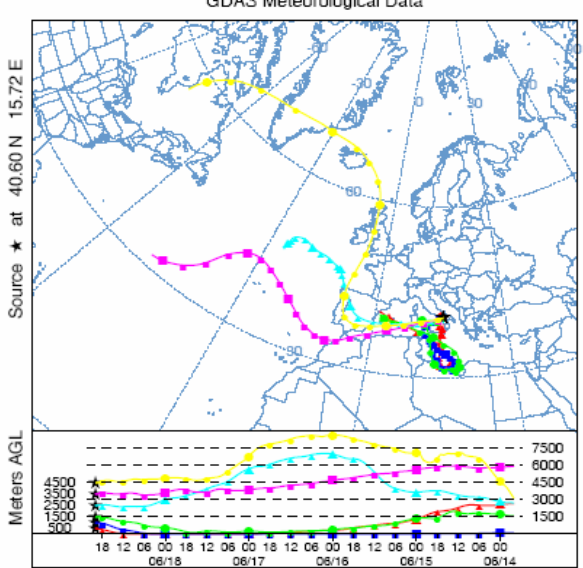

C DREAy Dust Looding $(g / m a 2)$ and $3000 \mathrm{~m}$ wind

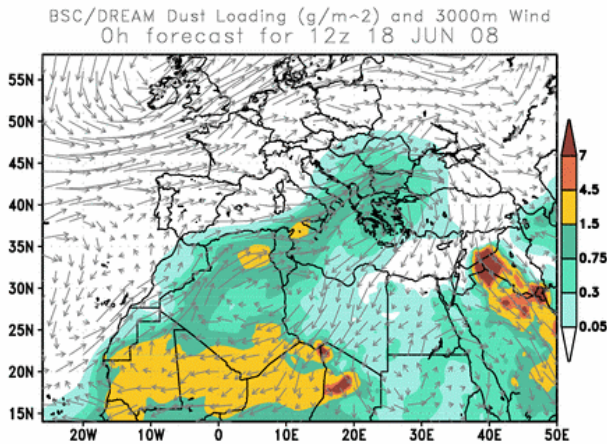

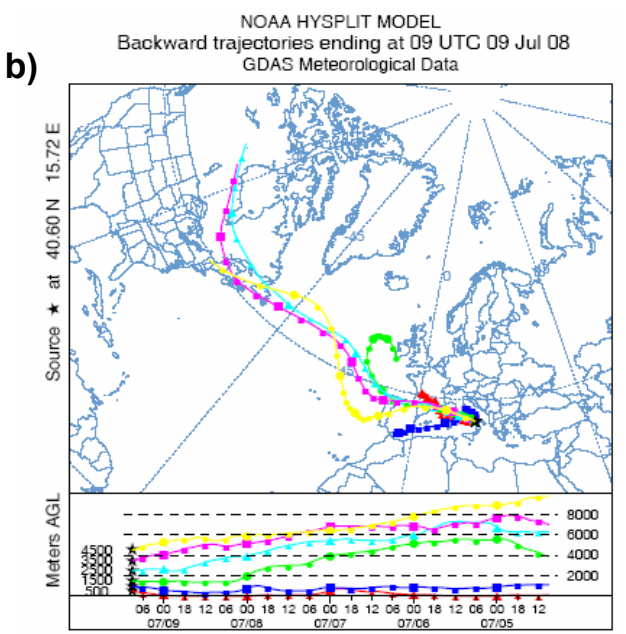

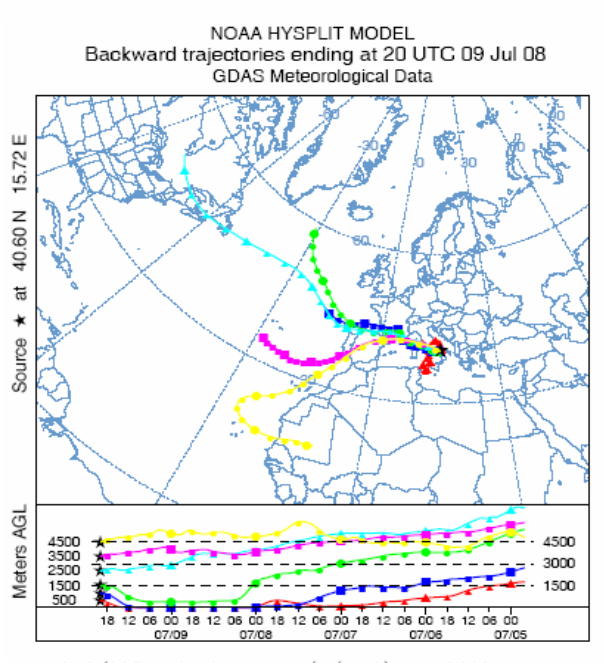

BSC/DREAM Dust Loading $(\mathrm{g} / \mathrm{m} \sim 2)$ and $3000 \mathrm{~m}$ Wind

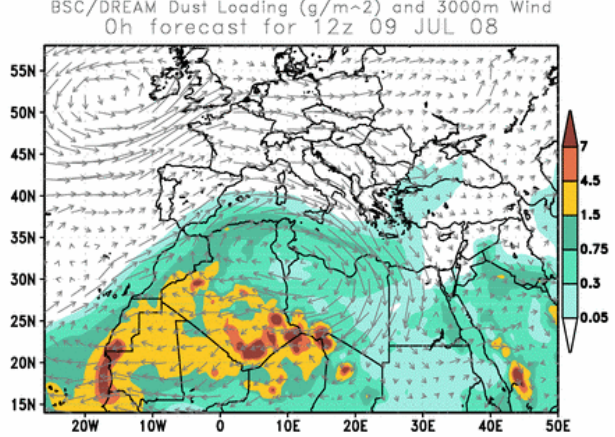

Fig. 2. (a) Back-Trajectories for 18 June at 10:00 UTC and 20:00 UTC and DREAM map for 12:00 UTC of the same day . (b) BackTrajectories for 9 July at 09:00 UTC and 20:00 UTC and DREAM map for 12:00 UTC of the same day .

their mass size distributions commonly show two modes, one sub-micrometer less intense and one more intense in the coarse range particle between 5 and $10 \mu \mathrm{m}$ (Eleftheriadis et al., 2006; Smirnov et al., 2002) suggesting that marine aerosol in our case mainly contribute to the coarse mode at about $6.6 \mu \mathrm{m}$.
In Table 1, for each measured size distribution, values of modal EAD are reported for both bimodal and multimodal mass size distributions. Looking at the variety of mass size distributions obtained, and analysing transport phenomena by back-trajectories, NAAPS and DREAM maps, it has been possible to verify how different aerosol types contribute to the different modes. In particular Saharan dust loading results in a distribution with the mode at $2.4 \mu \mathrm{m}$ dominating on 


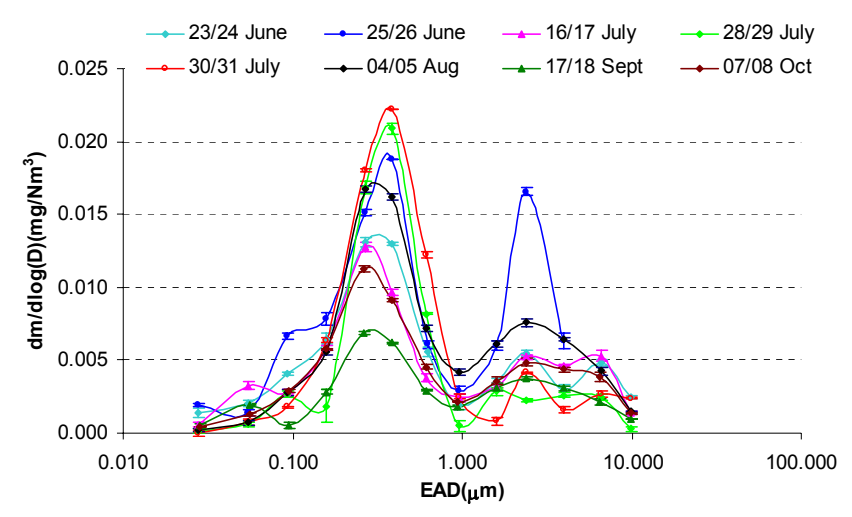

Fig. 3. Mass size distributions at ground level from DLPI data for 23/24 and 25/26 June, 16/17, 28/29 and 30/31 July, 4/5 August, 17/18 September and 7/8 October. Accumulation mode at about $0.3 \mu \mathrm{m}$ prevails on the coarse mode at $2.4 \mu \mathrm{m}$.

the fine one as plotted in Fig. 1. In all these cases Saharan dust intrusions influence the size distributions but with different intensity and duration. On 18/19 June, 7/8 July and 8/9 September, the contribution of transport from Africa remains strong almost all $24 \mathrm{~h}$ DLPI measurements long, with air masses travelling very low on Sahara region and on the Mediterranean Sea. This allows particles to be caught also from the sea resulting in an enhanced loading over the entire dimensional range. These features are showed for the representative day of 18/19 June in Fig. 2a, where the corresponding DREAM map is reported to verify the high intensity of Saharan air masses advection over our region. Mass size distributions for 9/10 July and the 14/15 July are characterised by the two less intense modes. As showed in Fig. 2b for the representative case of 9/10 July, back-trajectories in most cases do not directly come from the Saharan desert, loading up dust particles when travelling over the Mediterranean Sea, as it is possible to see also from DREAM map. Note that back trajectories reported in Fig. 2 are all calculated with their arrival time almost coincident with the first hours of DLPI sampling to take into account the deposition time of dust particles (Cachorro et al., 2008; Mukai et al., 2007).

Similarly, anthropogenic loading from North-Eastern Europe air masses transport results in distributions with the accumulation mode at about $0.3 \mu \mathrm{m}$ dominating on the coarse one at $2.4 \mu \mathrm{m}$ as plotted in Fig. 3. Depending on the strength of transport phenomena and on trajectories paths, the relative intensity of the two modes change. On 25/26 June, 28/29 and 30/31 July similar transport conditions from the NorthEastern Europe polluted area result in an intense prevailing fine mode. Back-trajectories are shown for the representative day of 28/29 July in Fig. 4a together with NAAPS map for sulphate concentration that is very high over the area. For 25/26 June in particular, mixed anthropogenic, smoke and dust aerosols are responsible for both modes to be very in- tense. As shown in Fig. 4b, on 4/5 August, air masses are mainly of marine origin but a strong local smoke event influences mass-size distribution leading to the fine mode prevailing on the coarse one. The mass size distributions for 23/24 June, 16/17 July and 7/8 October show a prevailing fine mode less intense in comparison with the days described before. In Fig. 4c, NAAPS map, for the representative case of 7/8 October, showing the absence of particular loading, has been reported. In these last cases back trajectories are mainly of marine origin. Finally, the mass size distribution for $17 / 18$ September is characterised by the lowest values of modal intensity both for the fine and the coarse mode. This is representative of a very back-ground situation since the measures have been preceded by a week lasted rain event that cleaned the air from aerosol burden.

\subsection{Columnar properties}

Daily averaged optical columnar properties of aerosols as measured by Ocean Optics S2000 radiometer from May to September 2008 are presented in Table 2. In particular the values of AOD at $500 \mathrm{~nm}$ and $780 \mathrm{~nm}$ together with Ångström parameters $\alpha$ and $\beta$ are reported, each with the corresponding standard deviation. For the entire analysis period a mean value of AOD@ $@ 500 \mathrm{~nm}$ of $0.26 \pm 0.01$ has been registered with a maximum value of $0.51 \pm 0.01$ on 28 May and a minimum of $0.11 \pm 0.01$ on 16 July. As regards $\alpha$, it oscillates between a minimum of $0.33 \pm 0.01$ on 8 July and a maximum of 1.91 on 30 July with a mean value of $1.12 \pm 0.04$. The mean AOD and $\alpha$ values are comparable to those reported in literature for rural sites similar to ours. In particular, our value for AOD@500 nm is in the middle between a mean value of AOD@ $440 \mathrm{~nm}$ of about $0.2(\alpha \sim 1.0)$, reported by Toledano et al. (2007), as measured during summer months on an multi-annual analysis basis for a Western Mediterranean semi-rural site, and a mean value of 0.29 for AOD@550 nm obtained by Schapp et al. (2009) on annual basis for a rural site in the Netherlands. In the case of Toledano et al. (2007), the site is characterized by advection phenomena similar to ours (continental air masses and Saharan dust intrusions), but with a larger prevalence of marine aerosol component. Grouping the days with similar optical properties and analysing back-trajectories, DREAM and NAAPS maps it is possible to identify aerosol impacting the measurement site as previously done with DLPI measurements. In particular Saharan dust, anthropogenic, and marine particles from transport phenomena have been detected together with back-ground aerosols, as showed in Table 3. In Fig. 5, a scatter plot of daily averaged values of AOD@780 nm and $\alpha$ has been reported as an instrument to interpret data by integrating the information on aerosol size and loading. Almost all data points lie in three different zones of the graph: points circled by the green ellipse are associated with values of AOD@780 nm between 0.1 and 0.2 and $\alpha$ between 1.1 and 3.0 and are related to days of 
a)

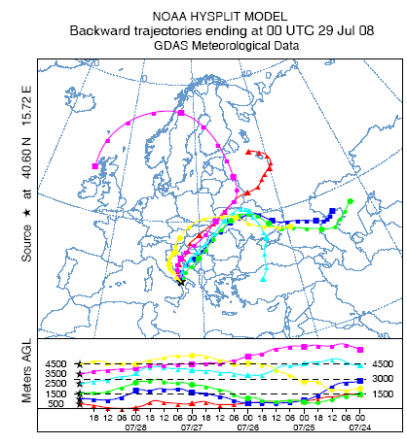

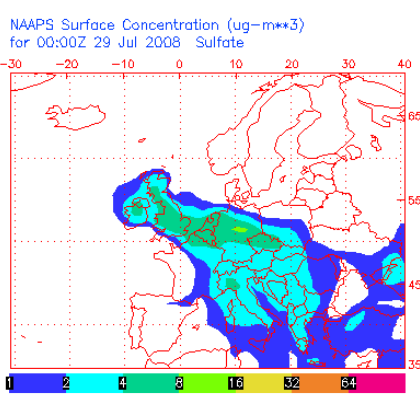

b)

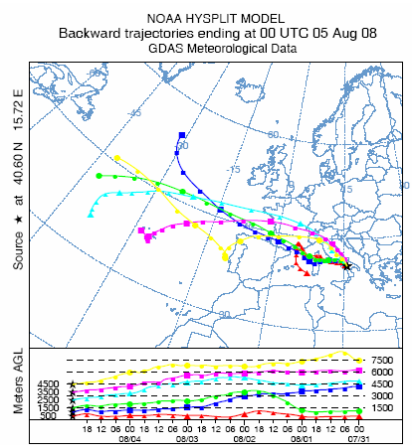

NAAPS Surface Concentration (ug-m**3)

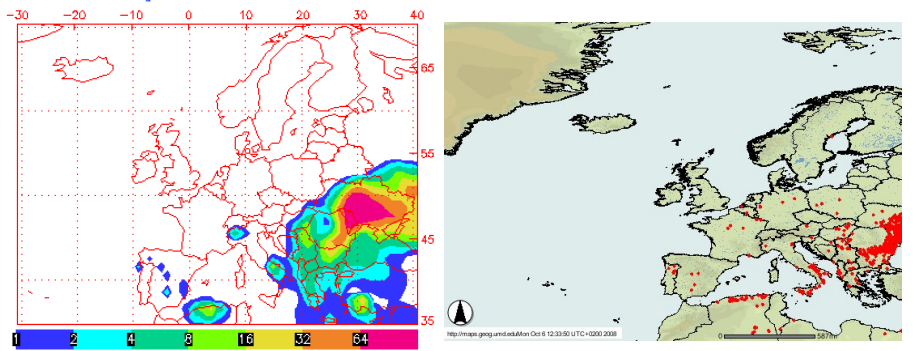

c)
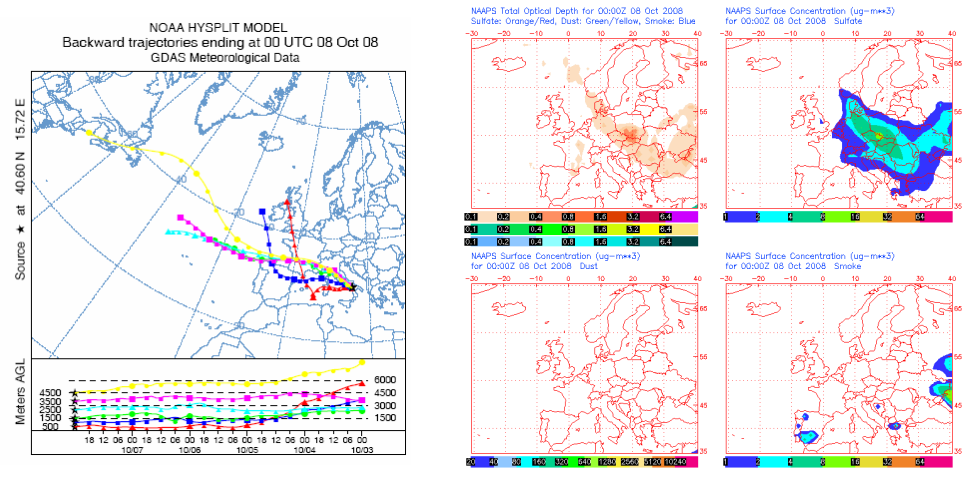

(2)

Fig. 4. (a) Back-Trajectories and NAAPS maps for sulphate concentrations for 29 July at 00:00 UTC. (b) Back-Trajectories, NAAPS maps for smoke concentrations and FIRMS map for 5 August at 00:00 UTC. (c) Back-Trajectories and NAAPS maps for 8 October at 00:00 UTC.

continental mass loading, anthropogenic and smoke aerosols, as checked with data analysis support tools (back trajectories, NAAPS, FIRMS). Points circled by the red ellipse with values of $\mathrm{AOD}>0.2$ and values of $\alpha<0.5$ are verified to be related to dust events. Points circled by the blue ellipse with both low values of AOD, $<0.1$ and $\alpha$ between 0.7 and 1.3, are related to days with only relevant transport phenomena of air masses coming from the sea.

In Fig. 6, spectral AOD behaviour, and corresponding number and volume columnar size distributions are presented for three selected days characterized by different aerosol loading. Flatter curve for AOD vs. $\lambda$ is found for dust episode on 8 July (a). As regards number size distributions (b), their are unimodal Junge functions for back-ground/marine and polluted case of 16 and 30 July, respectively. Dust size distributions are bimodal with a coarse mode centred at $0.94 \mu \mathrm{m}$ in agreement with what found in Pavese et al. (2009), where a transition from no-dust to dust atmospheric burden on a daily basis has been highlighted. Volume size distributions (c) are dominated by the fine size fraction in the case of polluted/smoke episode while the coarse mode prevalence characterizes dust one (Cachorro et al., 2008; Pietruczuk and Chaikovsky, 2007). Note that the prevailing fine mode for volume size distribution on 16 July confirms the presence of some smoke aerosols in transit during the measurements, as annotated by the operator during radiometric measurements. 


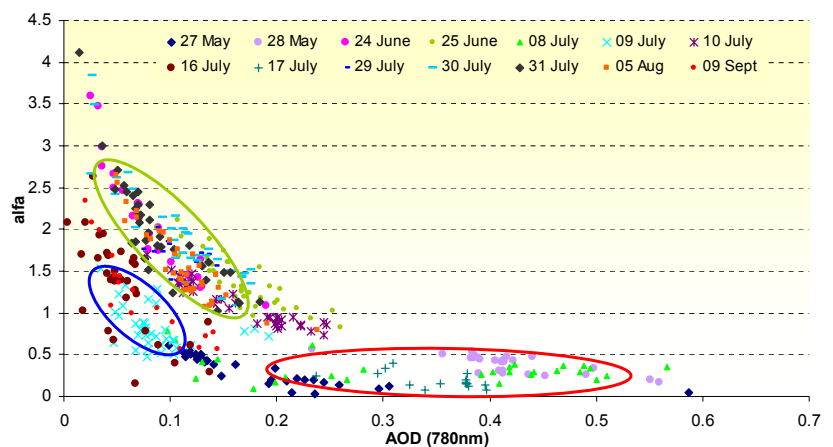

Fig. 5. Scatter plot of $\alpha$ and AOD@780 nm values.

\subsection{Comparing ground level and columnar size distributions}

Considering only contemporary radiometric and gravimetric measurements, agreement has been found in the identification of aerosol types associated with different air masses history from measurements obtained with the two different instruments as reported in Fig. 7. In this figure, daily averaged columnar AOD@780 nm and $\alpha$ values are shown together with the contributions of the fine and coarse particles fractions, $M_{1}$ and $M_{2}$, to the surface mass size distributions. $M_{1}$ and $M_{2}$ are calculated as the sum of $d m / d \log (D)$ values (Eq. 1) in the interval $\mathrm{EAD}<1 \mu \mathrm{m}$ and $\mathrm{EAD}>1 \mu \mathrm{m}$, respectively. Note that, due to the two instruments different sampling times, only diurnal hours of DLPI sampling coincide with radiometric measurements. This could explain the poor agreement in cases where air masses undergo changes in their origins and paths during the $24 \mathrm{~h}$ or where the effective coinciding hours of measurements are few. This is the case of 8/9 September when very different air masses transport phenomena affect night and day measurements hours as we will see better later.

In other cases, days with high values of $\alpha$ parameter and intermediate values of AOD@780 nm measured over the atmospheric column, identified in Fig. 5 as the points circled by the green ellipse, correspond to the higher fraction of small particles measured at the ground by DLPI (23/24 June, $30 / 31$ July and 4/5 August). For dust event of 7/8 July, high value of AOD@780 nm (0.34 \pm 0.04$)$ and minimum value of $\alpha$ parameter $(0.33 \pm 0.01)$ correspond to an enhancement of coarse/small particles ratio measured at the ground. For $25 / 26$ June both higher values of $\alpha$ parameter $(1.38 \pm 0.02)$ and AOD $(0.17 \pm 0.01 @ 780 \mathrm{~nm})$ together with both intense mode for surface mass size distribution suggest an aerosol mixing with different components summing up in a substantial loading. Days such as $9 / 10$ July and 16/17 July, with intermediate values of $\alpha(0.82 \pm 0.02$ for 9 July and $1.33 \pm 0.04$ for 16 July) and low value of AOD@ $980 \mathrm{~nm}(0.09 \pm 0.01$ for 9 July and $0.11 \pm 0.06$ for 16 July), correspond to both mode
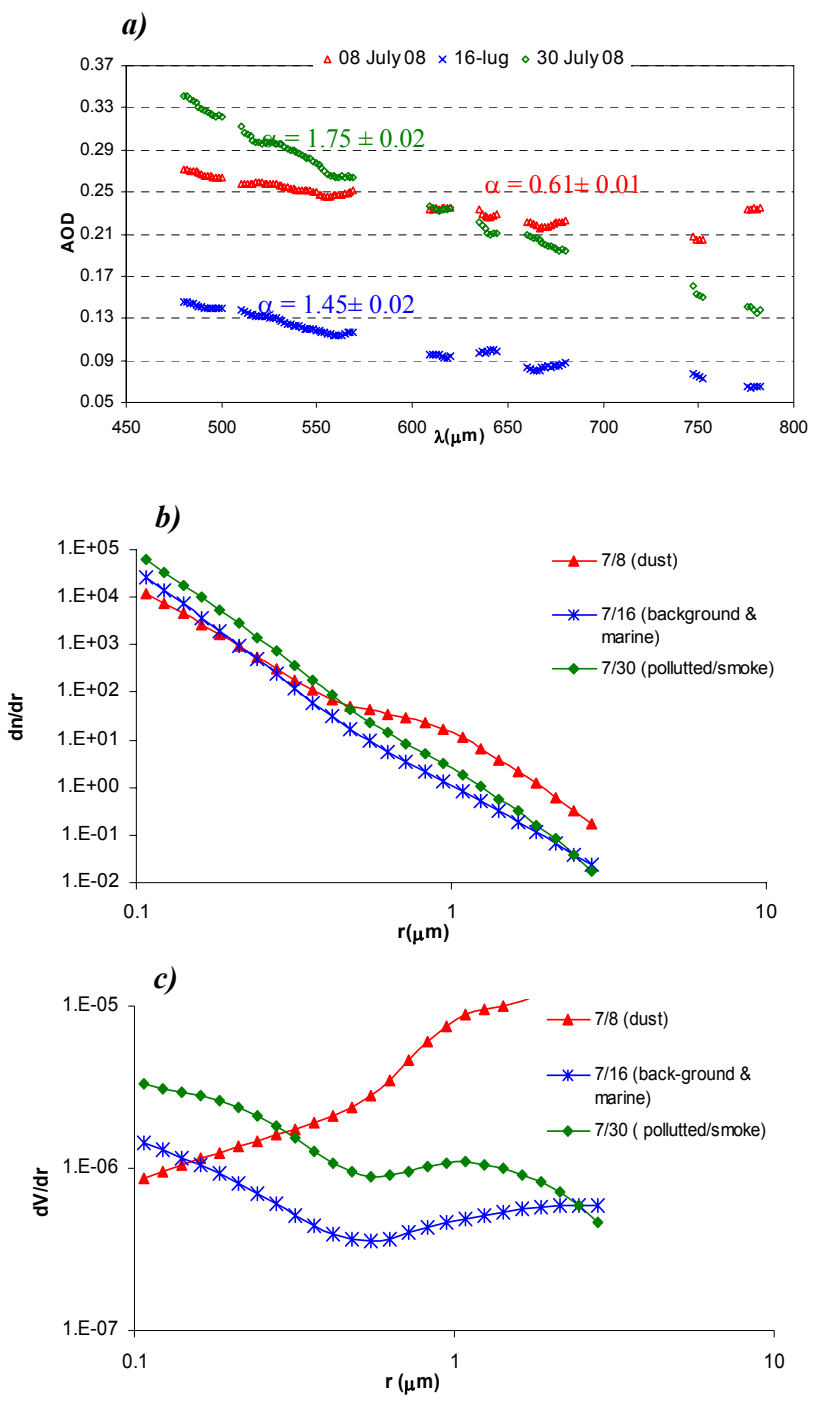

Fig. 6. (a) AOD vs. $\lambda$ for three selected days characterized by different aerosol loading: $(\Delta)$ dust, $(\times)$ back-ground and marine, $(\diamond)$ pollutted/smoke. Alpha value for each curve is reported in the graph. (b) Daily mean columnar number size distributions for the three selected days. (c) Daily mean columnar volume size distributions for the three selected days.

of DLPI distributions intermediate between maximum values of 25/26 June and minimum values of 17/18 September (see Fig. 3).

To analyze thoroughly the relation between columnar and surface data, values of the effective radius from radiometric derived volume size distributions have been converted to EAD assuming spherical particles and known values of the density. In particular an average value of $1.5 \mathrm{~g} \mathrm{~cm}^{-3}$ has been assumed for the density of fine particles as assessed in Kannosto et al. (2008) with a study on mode resolved density of fine aerosols particles. This value is the same reported in other correlated studies (McMurry et al., 2002; 
Saarikoski et al., 2005; Virtanen et al., 2006). A mean value of $2 \mathrm{~g} \mathrm{~cm}^{-3}$ has been used for coarse particles according to the work of Tegen et al. (2006), where the authors used this value to model dust particles starting from experimental data. In Fig. 8, columnar volume size distributions $n_{v}(D)$ and mass size distributions at ground level $n_{M}(D)$ have been plotted for the days of contemporary measurements. It is important to point out that for columnar distributions mean daily values have been considered. Another noteworthy aspect to be considered is the different dimensional range extent between radiometric and DLPI data since the reliability of radiometric inversion technique is limited to the 0.1$3.0 \mu \mathrm{m}$ dimensional range whereas impactor distributions extend from $0.03 \mu \mathrm{m}$ to $10 \mu \mathrm{m}$. Looking at Fig. 8 , a first remark is about the case of dust episode of 7/8 July (c) when coarse mode prevalence is more evident for radiometric measurement than for impactor one. Referring to Sect. 3.1, this is the case of an almost constant transport from Sahara during the $24 \mathrm{~h}$, without substantial changes between contemporary and no-contemporary measurement hours. Notwithstanding this, the high dust layers seem to affect columnar data in a more intense way than surface ones. This allows to agree with Smirnov et al. (2000), in the definition of a Saharan Air Layer (SAL) not always affecting low atmospheric layers. In Pace et al. (2006) an indication is found of a height between 4 and $8 \mathrm{~km}$ for dust transport from Sahara over the Mediterranean basin as obtained from LIDAR measurements. This aspect partly influences the measurement of 23/24 June (a) too, when the last part of the day, coinciding with the last part of DLPI sampling, is interested by the arrival of air masses from Africa with ending altitude of $3500-6000 \mathrm{~m}$ as verified from Hysplit model. These dust aerosols poorly contribute to the coarse mode of DLPI distribution also for the delay in deposition at ground. Mixing situation of 25/26 June (b) has been revealed by the two instruments with the fine and coarse modes amplitude of about the same magnitude measured both at the ground and on the column. The same is for 9/10 July (d) even with a lower aerosol loading. For 8/9 September (h) there is a huge difference in air masses paths between diurnal and nocturnal hours. DLPI measurement in fact, is influenced by a contribution of air masses arriving from Africa that is almost completely absent in radiometric measurement. For 16/17 July (e), 30/31 July (f) and 4/5 August (g) both ground and columnar distributions show a fine mode dominating the coarse one but with modal diameters for the fine fraction shifted to lower values in the case of columnar data. This could be explained by two reasons. First, in the case where aerosol loading is mainly attributed to fine particles, using a mean value of $1.5 \mathrm{~g} \mathrm{~cm}^{-3}$ for the density of fine particles leads to an overestimation of the true value. Second cause is the effective difference between concentrations at ground and over the column. This is due to the fact that anthropogenic loading events are often originated by sources near the ground, this being in some cases the main component of aerosols sampled at ground but

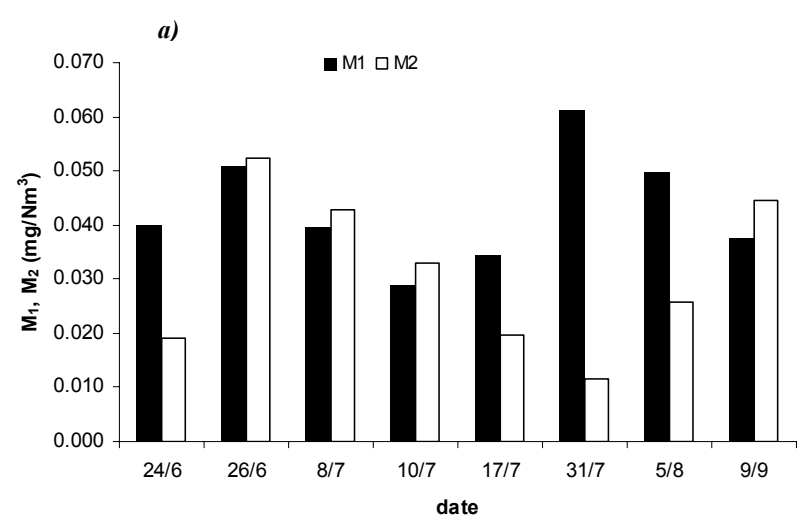

b)

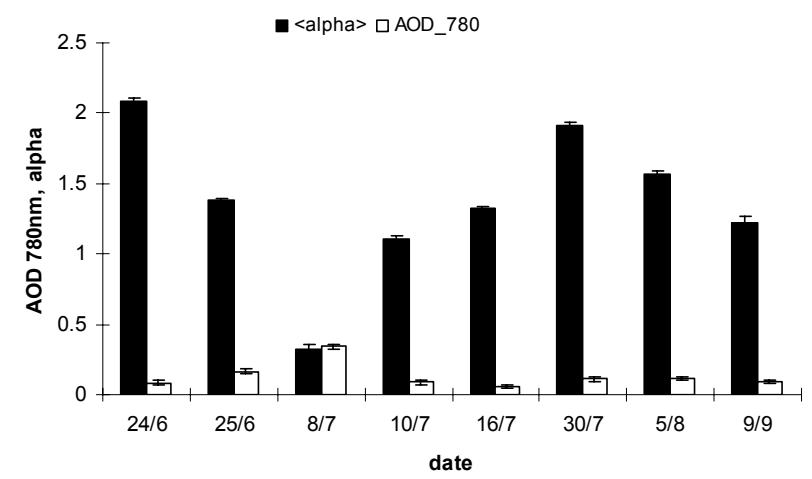

Fig. 7. (a) Temporal variation of $M_{1}$ and $M_{2}$ for days of contemporary measurements by DLPI and radiometer. $M_{1}$ and $M_{2}$ correspond to the sum of $d m / d \log (D)$ (Eq. 1) values in the interval $\mathrm{EAD}<1 \mu \mathrm{m}$ and $\mathrm{EAD}>1 \mu \mathrm{m}$, respectively. Dates in the graph (a) refer to the second day of the $24 \mathrm{~h}$ impactor sampling. (b) Temporal variation of daily averaged values of AOD@780 nm and of $\alpha$ for days of contemporary measurements by DLPI and radiometer.

not so important when data are integrated on the atmospheric column as for radiometric measurements (Gerasopoulos et al., 2007). On the other side, for these three days, fire smoke aerosols transported at high altitude (Lyamani et al., 2008; Pietruczuk and Chaikovsky, 2007) cause columnar measurements to reveal a larger amount of fly ash fine particles.

\subsection{Black carbon concentrations}

Figure 9 shows hourly averaged values of 7 -wavelenghts $(\lambda=370,470,520,590,660,880,950 \mathrm{~nm})$ BC concentrations for some selected periods between May 2008 to August 2008 almost coinciding with periods analysed for radiometric and DLPI measurements. In particular daily variations are reported from 27 May to 5 June (a), from 18 June to 1 July (b) and from 29 July to 8 August (c). Daily trend is characterised, for most of the working days (Monday to Thursday), by two peaks with concentrations values@880 nm between 2000 and $4000 \mathrm{ng} / \mathrm{m}^{3}$ : one in the morning between 

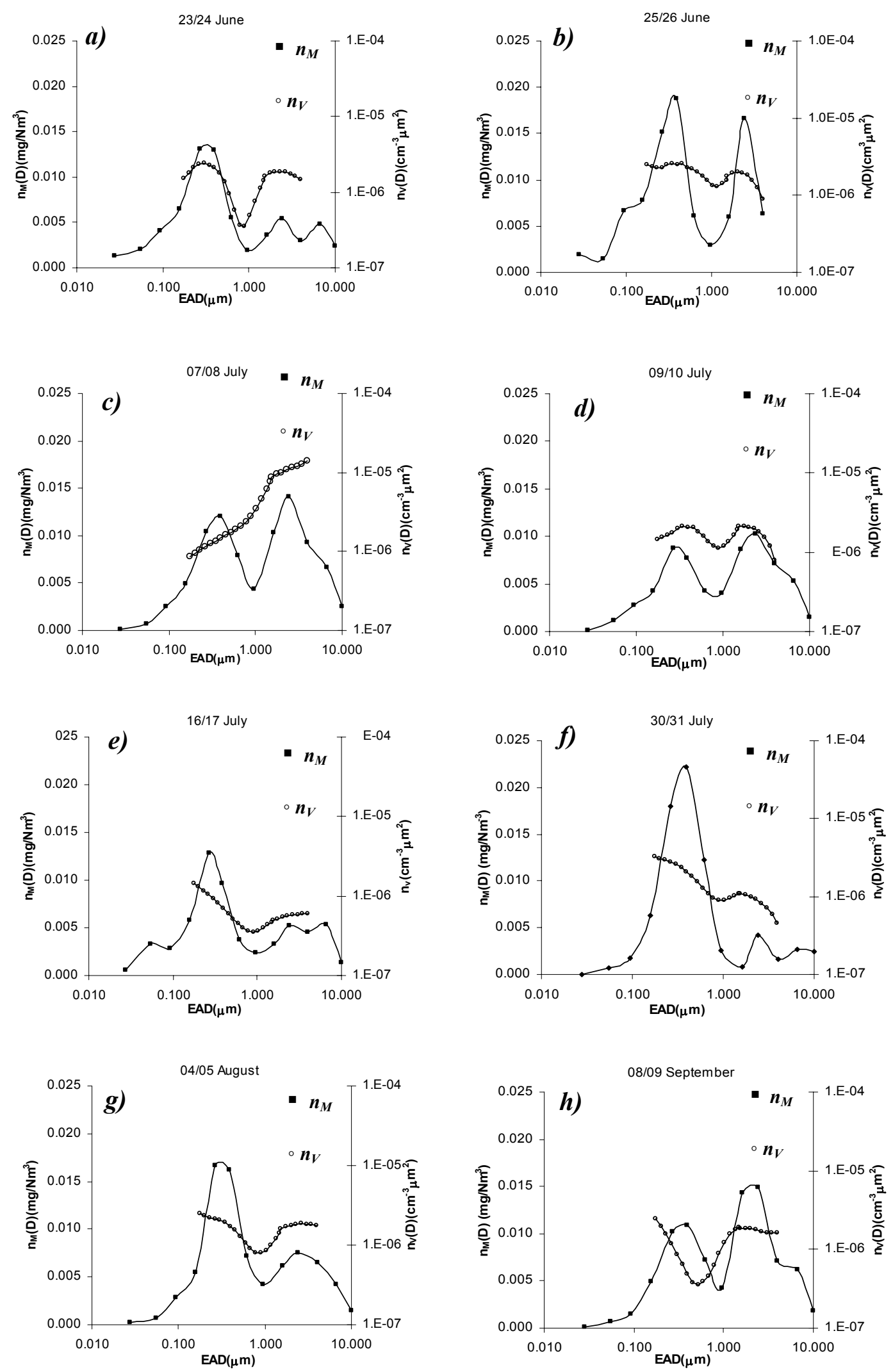

Fig. 8. Comparison of columnar volume size distributions $n_{V}(D)$ (o) and mass size distribution at ground level $n_{M}(D)$ (-) for $23 / 24$ June (a), 25/26 June (b), 7/8July (c), 9/10 July (d), 16/17 July (e), 30/31 July (f), 4/5 August (g), 8/9 September (h). 

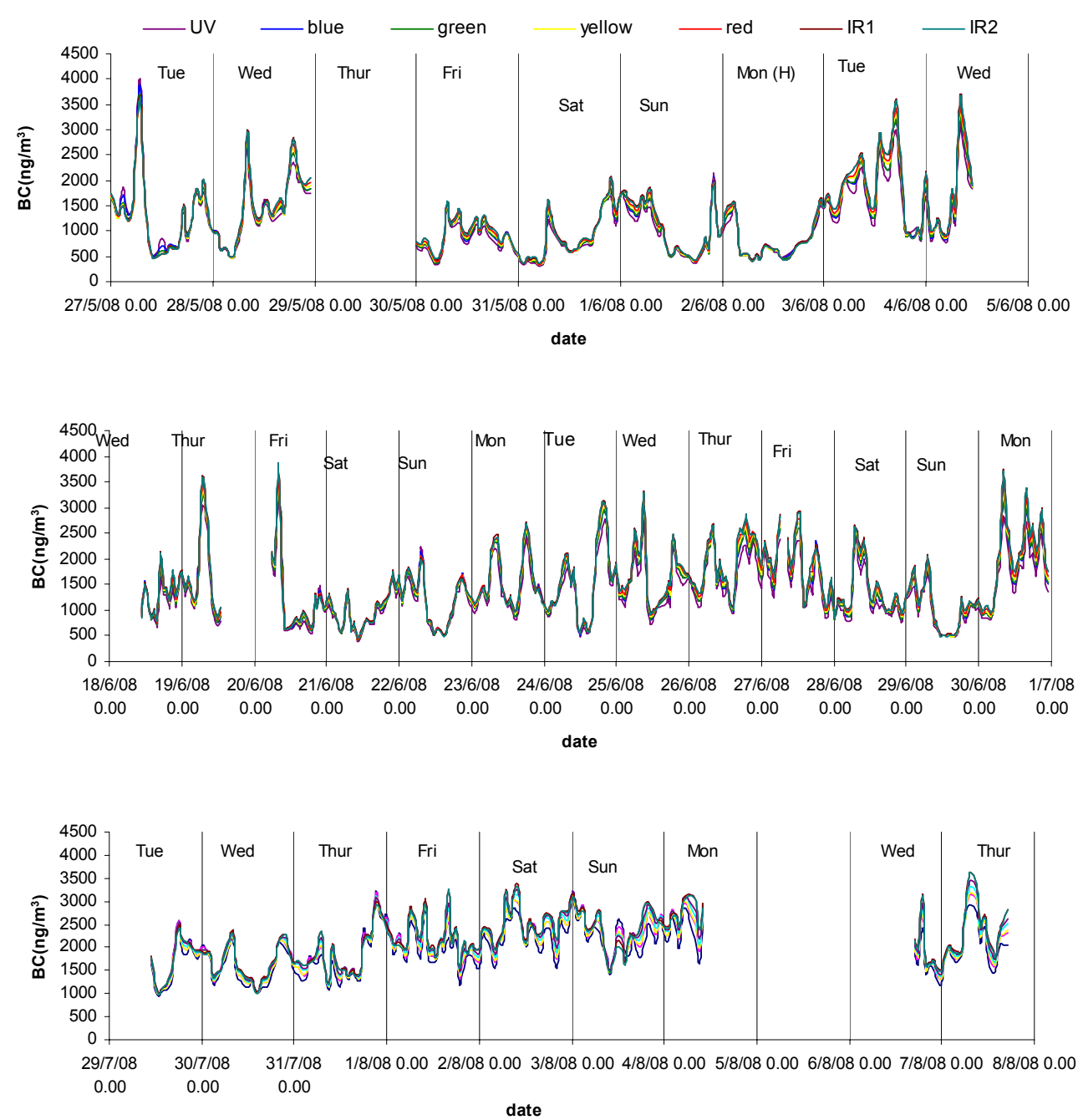

Fig. 9. Hourly averaged values of 7-wavelenghts ( $\lambda$ 370, 470, 520, 590, 660, 880, $950 \mathrm{~nm}) \mathrm{BC}$ concentrations for three selected period between May 2008 to August 2008: 27 May-5 June (a), 18 June-1 July (b), and 29 July-8 August (c).

07:00 and 08:00 UTC and one in the evening between 17:00 to 20:00 UTC. A more variable behaviour has been found for week-end days without definite modes and with overall lower concentrations of about $2000 \mathrm{ng} / \mathrm{m}^{3}$ at maximums. This suggests that local traffic is the main source of black-carbon at the site. Looking at panel $c$, it is possible to note that daily trends are lost due to the strong smoke/pollution longrange transport event registered from 29 July to 5 August and described before (see Sects. 3.1 and 3.2). For this period minimum threshold is shifted to higher values of about $1000 \mathrm{ng} / \mathrm{m}^{3}$ also for week-end days.

Considering only contemporary measurements, in the graphic in Fig. 10, the temporal variation of daily averaged values of $n_{1}$ (columnar fine fraction particle concentration) as obtained from radiometric measurements, of BC (surface black carbon concentration@880 nm) as measured by aethalometer, and of $M_{1}$ (surface fine fraction mass) as obtained from DLPI measurements, are reported. Note that

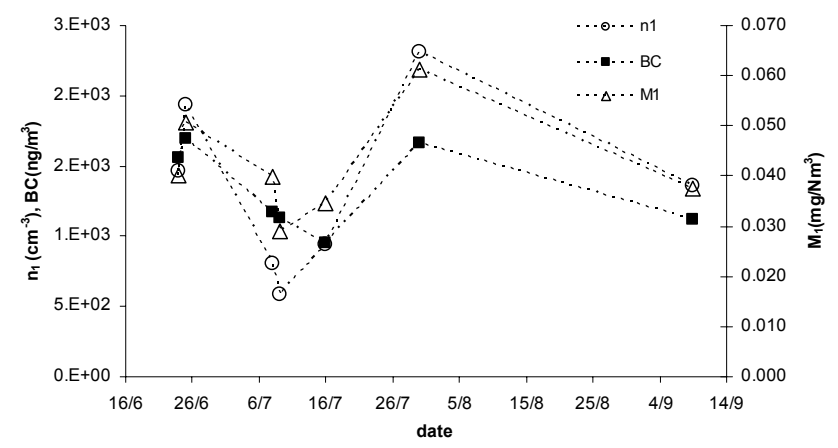

Fig. 10. Temporal variations of $n_{1}$ (daily averaged columnar fine fraction particle concentration), of BC (daily averaged surface black carbon concentration, $880 \mathrm{~nm}$ ), and of $M_{1}$ (daily averaged surface fine fraction mass) for contemporary measurements days. 
for DLPI and aethalometer sampling, averages are calculated over $24 \mathrm{~h}$, whereas for radiometer only diurnal measurements are available. Lower values of $M_{1}, n_{1}$ and $\mathrm{BC}$ are found during dust event (8 July) and for back-ground aerosol condition (9 and 16 July). Maximum values correspond to anthropogenic loading due to air masses transport from Eastern Europe (25 June and 30 July). For these days BC local component is enhanced by polluted incoming aerosol particles.

\section{Conclusions}

Atmospheric aerosol optical and physical properties have been studied with the combined use of in-situ (impactor and aethalometer) and radiometric remote sensing measurements in a semi-rural site in Southwest Italy from May to October 2008. Analysis of different types of data obtained allowed to coherently characterize atmospheric aerosol present at the site and to register, from time to time, changes in aerosol burden associated with variation of transport phenomena. In particular dust episodes have been simultaneously identified from optical radiometric derived properties, with a maximum daily averaged value of AOD@780 nm and minimum value of $\alpha$ parameter, and from mass size distributions measured at the ground, with the coarse fraction prevailing on the fine one. In the case of pollution events associated with continental air masses coming from East Europe, an enhancement of $\alpha$ parameter and of AOD@500 nm, corresponds to a fine fraction dominant on the coarse one for distributions measured at ground.

Further, considering aethalometer measurements, increased values of $\mathrm{BC}$ concentration have been found for transported anthropogenic aerosol. For these cases, daily trends characterized by two peaks for most of the working days and no definite modes plus overall lower concentrations, for week-end days, are lost. In particular, the minimum concentration threshold is shifted to higher values of about $1000 \mathrm{ng} / \mathrm{m}^{3}$ also for week-end days. Daily trend for the working days suggests that local traffic (a main road passes at a distance of about $1 \mathrm{~km}$ ) is the main source of black-carbon at the site.

A direct comparison between impactor mass-size distributions and columnar volume size distributions has been performed to complete the study of integrated data. In the case of Saharan dust event, dust particles seem to dominate aerosol optical properties within the column: comparison with in-situ measurements reveals in this case an underestimate in coarse particles detection at the ground level. For anthropogenic transported and local produced aerosols, a better agreement is found suggesting that in this case, surface aerosols optical properties dominate columnar integrated data.
Limitation in correlating surface and columnar measurements has been represented in our work by instruments different sampling times and conditions, since only diurnal hours of DLPI sampling coincide with radiometric measurements. This taken into account, from the obtained results it has been possible to study links between aerosols in the near-ground layer of the atmosphere and aerosols over the column also in cases when different layers of aerosols at different heights are present, thus reducing degrees of freedom in aerosol properties study.

On the whole, representativeness of ground-level data for columnar ones has been verified, in agreement with what found in Mukai et al. (2007), Shaap et al. (2009) and Shäfer et al. (2008).

The necessity in expanding spatial and temporal coverage for integrated measurements represents a stimulus to extend the database to include seasonal patterns of aerosol properties.

Edited by: A. Petzold

\section{References}

Barnaba, F., Tafuro, A. M., De Tomasi, F., and Perrone, M. R.: Observed and simulated vertically resolved optical properties of continental aerosols over southestern Italy: A closure study, J. Geophys. Res., 112, D10203, doi:10.1029/2006JD007926, 2007.

Baron, P. A. and Willeke, K.: Aerosol Measurements. Principles, Techniques, and Application, Wiley \& Sons, Inc., New York, USA, 2001.

Cachorro, V. E., Toledano, C., Prats, N., Sorribas, M., Mogo, S., Berjón, A., Torres, B., Rodrigo, R., de la Rosa, J., and De Frutos, A. M.: The strongest desert dust intrusion mixed with smoke over the Iberian Peninsula registered with Sun photometry, J. Geophys. Res., 113, D14S04, doi:10.1029/2007JD009582, 2008.

Chaudhry, Z., Vanderlei Martins, J., Li, Z., Tsay, S., Chen, H., Wang, P., Wen, T., Li, C., and Dickerson, R. R.: In situ measurements of aerosol mass concentration and radiative properties in Xianghe, southeast of Beijing, J. Geophys. Res., 112, D23S90, doi:10.1029/2007JD009055, 2007.

Cheng, T., Zhang, R., Han, Z., and Fang, W.: Relationship between ground-based particle component and column aerosol optical property in dusty days over Beijing, Geophys. Res. Lett., 35, L20808, doi:10.1029/2008GL035284, 2008.

Choi, I., Kim, S., Kim, J., Yoon, S., Kim, M., Sugimoto, N., Kondo, Y., Miyazaki, Y., Moon, K., and Han, J.: Characteristics of the transport and vertical structure of aerosols during ABCEAREX2005, Atmos. Environ., 42, 8513-8523, 2008.

Chuaybamroong, P., Wu, C., and Lundgren, D. A.: Aerosol source sampling in a mid-scale city, Gainesville, FL, Aerosol Air Qual. Res., 6, 213-230, 2006.

Clarke, A. D., Wu, C., Shinozuka, Y., Kapustin, V. N., Howell, S., Huebert, B., Doherty, S., Anderson, T., Covert, D., Andersen, J., Hua, X., Moor, K. J., McNaughton, C., Carmichael, G., and Weber, R.: Size distributions and mixtures of dust and black carbon aerosol in Asian outflow, Physiochemistry and optical properties, 
J. Geophys. Res., 109, D15S09, doi:10.1029/2003JD004378, 2004.

Collaud Coen, M., Weingartner, E., Apituley, A., Ceburnis, D., Flentje, H., Henzing, J. S., Jennings, S. G., Moerman, M., Petzold, A., Schmidhauser, R., Schmid, O., and Baltensperger, U.: Minimizing light absorption measurement artifacts of the Aethalometer: evaluation of five correction algorithms, Atmos. Meas. Tech. Discuss., 2, 1725-1770, 2009,

http://www.atmos-meas-tech-discuss.net/2/1725/2009/.

Draxler, R. R. and Rolph, G. D.: HYSPLIT (Hybrid Single-Particle Lagrangian Integrated Trajectory) model, http://www.arl.noaa. gov/ready/hysplit4.html, NOAA Air Resour. Lab., Silver Spring, MD, 2003.

Eleftheriadis, K., Colbeck, I., Housiadas, C., Lazaridis, M., Mihalopoulos, N., Mitsakou, C., Smolik, J., and Zdimal, V.: Size distribution composition and origin of the submicron aerosol in the marine boundary layer during the Eastern Mediterranean "SUB-AERO" experiment, Atmos. Environ., 40, 6245-6260, 2006.

Esposito, F., Leone, L., Pavese, G., Restieri, R., and Serio, C.: Seasonal variation of aerosol properties in South Italy: a study on aerosol optical depths, Ångström turbidity parameters and aerosol size distributions, Atmos. Environ., 38, 1605-1614, 2004.

Gerasopoulos, E., Koulouri, E., Kalivitis, N., Kouvarakis, G., Saarikoski, S., Mkel, T., Hillamo, R., and Mihalopoulos, N.: Size-segregated mass distributions of aerosols over Eastern Mediterranean: seasonal variability and comparison with AERONET columnar size-distributions, Atmos. Chem. Phys., 7, 2551-2561, 2007,

http://www.atmos-chem-phys.net/7/2551/2007/.

IPCC: Intergovernmental Panel on Climate Change, Climate Change 2007: The Physical Science Basis: Contribution of Working Group I to the Fourth Assessment Report of the Intergovernmental Panel on Climate Change, Cambridge University Press, Cambridge, 2007.

Kannosto, J., Virtanen, A., Lemmetty, M., Mäkelä, J. M., Keskinen, J., Junninen, H., Hussein, T., Aalto, P., and Kulmala, M.: Mode resolved density of atmospheric aerosol particles, Atmos. Chem. Phys., 8, 5327-5337, 2008, http://www.atmos-chem-phys.net/8/5327/2008/.

Lyamani, H., Olmo, F. J., and Alados-Arboledas, L.: Saharan dust outbreak over southeastern Spain as detected by sun photometer, Atmos. Environ., 39, 7276-7284, 2005.

Lyamani, H., Olmo, F. J., and Alados-Arboledas, L.: Light scattering and absorption properties of aerosol particles in the urban environment of Granada, Spain, Atmos. Environ., 42, 2630-2642, 2008.

Masmoudi, M., Chaabane, M., Tanrè, D., Gouloup, P., Blarel, L., and Elleuch, F.: Spatial and temporal variability of aerosol: size distribution and optical properties, Atmos. Res., 66, 1-19, 2003.

McMurry, P., Wang, X., Park, K., and Ehara, K.: The relationship between mass and mobility for atmospheric particles: A new technique for measuring particle density, Aerosol Sci. Tech., 36, 227-238, 2002.

Mukai, S., Sano, I., Mukai, M., and Yasumoto, M.: Evaluation of air quality from space, in: Proceedings of SPIE - The International Society for Optical Engineering, 6745, 67451X.167451X.8, 2007.
Mukai, S., Sano, I., Satoh, M., and Holben, B. N.: Aerosol properties and air pollutants over an urban area, Atmos. Res., 82, 643651,2006

Pace, G., di Sarra, A., Meloni, D., Piacentino, S., and Chamard, P.: Aerosol optical properties at Lampedusa (Central Mediterranean), 1. Influence of transport and identification of different aerosol types, Atmos. Chem. Phys., 6, 697-713, 2006, http://www.atmos-chem-phys.net/6/697/2006/.

Papayannis, A., Balis, D., Amiridis, V., Chourdakis, G., Tsaknakis, G., Zerefos, C., Castanho, A. D. A., Nickovic, S., Kazadzis, S., and Grabowski, J.: Measurements of Saharan dust aerosols over the Eastern Mediterranean using elastic backscatter-Raman lidar, spectrophotometric and satellite observations in the frame of the EARLINET project, Atmos. Chem. Phys., 5, 2065-2079, 2005, http://www.atmos-chem-phys.net/5/2065/2005/.

Park, S. and Kim, J.: Aerosol size distributions observed at the Seoul National University campus in Korea during the Asian dust and no-dust periods, Atmos. Environ., 40, 1722-1730, 2006.

Pavese, G., De Tomasi, F., Calvello, M., Esposito, F., and Perrone, M. R.: Detection of Sahara dust intrusions during mixed advection patterns over south-east Italy: A case study, Atmos. Res., 92, 489-504, 2009.

Perrone, M. R., Santese, M., Tafuro, A. M., Holben, B., Smirnov, A.: Aerosol load characterization over South-East Italy for one year of AERONET sun-photometer measurements, Atmos. Res., 75, 111-133, 2005.

Pietruczuk, A. and Chaikovsky, A. P.: Properties of fire smoke in Eastern Europe measured by remote sensing method, in: Proceedings of SPIE - The International Society for Optical Engineering, 6745, 67451T.1-67451T.10, 2007.

Saarikoski, S., Mäkelä, T., Hillamo, R., Aalto, P., Kerminen, V., and Kulmala, M.: Physico-chemical characterization and mass closure of size-segregated atmospheric aerosols in Hyytiälä, Finland, Boreal Environ. Res., 10, 385-400, 2005.

Salma, I., Dal Maso, M., Kulmala, M., and Záray, G.: Modal characteristics of particulate matter in urban atmospheric aerosols, Microchem. J., 73, 19-26, 2002.

Schaap, M., Apituley, A., Timmermans, R. M. A., Koelemeijer, R. B. A., and de Leeuw, G.: Exploring the relation between aerosol optical depth and $\mathrm{PM}_{2.5}$ at Cabauw, the Netherlands, Atmos. Chem. Phys., 9, 909-925, 2009, http://www.atmos-chem-phys.net/9/909/2009/.

Schäfer, K., Harbusch, A., Emeis, S., Koepke, P., and Wiegner, M.: Correlation of aerosol mass near the ground with aerosol optical depth during two seasons in Munich, Atmos. Environ., 42, 40364046, 2008.

Smirnov, A., Holben, B. N., Kaufman, Y. J., Dubovik, O., Eck, T. F., Slutsker, I., Pietras, C., and Halthore, R.: Optical properties of atmospheric aerosol in maritime environments, J. Atmos. Sci., 59, 501-503, 2002.

Smirnov, A., Holben, B. N., Savoie, D., Prospero, J. M., Kaufman, Y. J., Tanre, D., Eck, T. F., and Slutsker, I.: Relationship between column aerosol optical thickness and in situ ground based dust concentrations over Barbados, Geophys. Res. Lett., 27, 16431646, 2000.

Snyder, D. C. and Schauer, J. J.: An Inter-Comparison of Two Black Carbon Aerosol Instruments and a Semi-Continuous Elemental Carbon Instrument in the Urban Environment, Aerosol Sci. Tech., 41(5), 463-474, 2007. 
Tegen, I., Heinold, B., Todd, M., Helmert, J., Washington, R., and Dubovik, O.: Modelling soil dust aerosol in the Bodélé depression during the BoDEx campaign, Atmos. Chem. Phys., 6, 43454359, 2006,

http://www.atmos-chem-phys.net/6/4345/2006/.

Toledano, C., Cachorro, V. E., Berjon, A., de Frutos, A. M., Sorribas, M. de la Morena, B. A., and Goloub, P.: Aerosol optical depth and Ångström exponent climatology at El Arenosillo AERONET site (Huelva, Spain), Q. J. Roy. Meteor. Soc., 133, 795-807, 2007.
Virtanen, A., Rönkkö, T., Kannosto, J., Ristimäki, J., Mäkelä, J. M., Keskinen, J., Pakkanen, T., Hillamo, R., Pirjola, L., and Hämeri, K.: Winter and summer time size distributions and densities of traffic-related aerosol particles at a busy highway in Helsinki, Atmos. Chem. Phys., 6, 2411-2421, 2006,

http://www.atmos-chem-phys.net/6/2411/2006/. 